\title{
Role of Social Knowledge Networking technology in facilitating meaningful use of Electronic Health Record medication reconciliation
}

\author{
Pavani Rangachari * \\ College of Allied Health Sciences, Augusta University, Georgia, United States
}

Received: February 22, 2016

DOI: $10.5430 /$ jha.v5n3p98

\author{
Accepted: March 30, 2016 \\ Online Published: April 11, 2016 \\ URL: http://dx.doi.org/10.5430/jha.v5n3p98
}

\begin{abstract}
Despite the federal policy impetus towards Electronic Health Record (EHR) medication reconciliation, hospital adherence has lagged for one chief reason; low physician engagement, which in turn emanates from lack of consensus in regard to which physician is responsible for managing a patient's medication list, and the importance of medication reconciliation as a tool for improving patient safety and quality of care. The Technology-in-Practice (TIP) framework stresses the role of human action in enacting structures of technology use or "technologies-in-practice". Applying the TIP framework to the EHR medication reconciliation context, helps frame the problem as one of low physician engagement in performing EHR medication reconciliation, translating to limited-use-EHR-in-practice. Concurrently, the problem suggests a hierarchical network structure, reflecting limited communication among hospital administrators and clinical providers on the importance of EHR medication reconciliation in improving patient safety. Integrating the TIP literature with the more recent knowledge-in-Practice (KIP) literature suggests that EHR-in-practice could be transformed from "limited use" to "meaningful use" through the use of Social Knowledge Networking (SKN) technology to create new social network structures, and enable engagement, learning, and practice change. Correspondingly, the objectives of this paper are to: (1) Conduct a narrative review of the literature on "technology use", to understand how technologies-in-practice may be transformed from limited use to meaningful use; (2) Conduct a narrative review of the literature on "organizational change implementation" to understand how changes in technology use could be successfully implemented and sustained in a healthcare organizational context; and (3) Apply lessons learned from the narrative literature reviews to identify strategies for the meaningful use and successful implementation of EHR medication reconciliation technology.
\end{abstract}

Key Words: Electronic Health Records; Medication reconciliation; Hospital adoption of Electronic Health Records; Meaningful use of health information technology; Social Knowledge Networking technology; Implementation science

\section{INTRODUCTION}

Healthcare reform efforts are increasingly focused on improving patient safety during care transitions, when patients are most vulnerable to medication errors. ${ }^{[1-5]}$ According to the Institute of Medicine, medication errors injure over 1.5 million people and cost billions of dollars each year in the United States; and the average hospitalized patient experiences at least one medication error each day. ${ }^{[6]}$ The risk of medication errors is increased during care transitions mainly because physicians and patients do not have access to updated medication lists, which in turn can result in inadvertent addition, omission, or duplication of medications,

*Correspondence: Pavani Rangachari; Email: prangachari@augusta.edu; Address: College of Allied Health Sciences, Augusta University, Augusta, GA 30912, United States. 
producing "unintended discrepancies" between what should be prescribed, and what is in fact prescribed. Unintended medication discrepancies affect up to $70 \%$ of hospital patients; and over one-third of these discrepancies have the potential to result in patient harm. ${ }^{[4,6]}$

To help prevent unintended medication discrepancies and errors during care transitions, patient safety advocates have long promoted the use of medication reconciliation. ${ }^{[7-10]}$ Medication reconciliation refers to the process of creating the most complete list of a patient's current medications, comparing the list to the medical record, and communicating the final updated list to the patient, family, caregivers, and the next providers of care. Medication reconciliation has been a part of the Joint Commission hospital accreditation requirements since 2005, and more recently, it has become part of the "Electronic Health Record (EHR) meaningful use" requirements. "Meaningful use" of EHR refers to use of certified EHR technology to improve the quality, safety, and efficiency of healthcare delivery, improve care coordination, engage patients and families in care delivery, and reduce healthcare disparities. Therefore, given the increased risk of medication errors during care transitions, the "meaningful use" of EHR medication reconciliation has potential to substantially improve quality and safety, reduce disparities $\&$ costs, and engage patients \& families in care delivery. In 2009 moreover, the federal government introduced incentive payments to hospitals and providers demonstrating "meaningful use" of certified EHR technology, through the Health Information Technology for Economic and Clinical Health (HITECH) Act. ${ }^{[11]}$

Despite the federal policy impetus towards EHR medication reconciliation, however, hospital adherence has lagged for one chief reason - low physician engagement - which in turn emanates from lack of consensus in regard to which physician is responsible for managing a patient's medication list, and the importance of medication reconciliation as a tool for improving patient safety and quality of care ${ }^{[12-14]}$ Particularly, the division of responsibilities among professional subgroups - nurses, generalist \& specialist physicians, and pharmacists - is often unclear, leading to error and inefficiency. ${ }^{[15]}$ A national study conducted in 2013 found that although hospital EHR vendors have been enhancing functionality associated with medication reconciliation over time, more than a third of the hospitals still use partially paperbased processes during transitions of care (e.g., admission and discharge). ${ }^{[13]}$

\section{NARRATIVE LiteratURE REVIEW}

Following from the background information described above, this paper seeks to address two key problems of interest:

Published by Sciedu Press
(1) limited use of EHR medication reconciliation technology by individual providers of care (e.g., physicians); and (2) ineffective implementation of EHR medication reconciliation technology within the hospital/healthcare organizational context. A narrative literature review methodology is used to specifically address these two problems of interest, and gain insights into how to overcome these challenges. In other words, a narrative literature review is directed specifically towards understanding: (1) how limited use of EHR technology could be converted to meaningful use of EHR technology; and likewise; (2) how ineffective EHR implementation could be transformed to a successful \& sustained implementation of EHRs, within a healthcare organizational context.

The longstanding Technology-in-Practice (TIP) framework emphasizes the role of human action in enacting structures of technology use or "technologies-in-practice". ${ }^{[16,17]}$ The TIP framework has been used by information technology (IT) researchers to trace back Unintended Adverse Consequences (UACs) of implementing health IT, to specific actions or "technologies-in-practice" while also linking them to institutional conditions or "social network structures". ${ }^{[18-21]}$ For example, the TIP framework has been used to trace the UAC of "conflicts between electronic and paper-based systems" back to "limited-use-TIP" and "hierarchical social network structures," i.e., a network structure characterized by limited communication across various organization levels, e.g., administrators and practitioners regarding the importance of the technology being implemented. In a similar vein, the TIP framework has also been used to detect unintended favorable consequences (UFCs) of IT implementation, e.g., improvisations in processes to "collective-problem-solving-TIP" alongside "collaborative social network structures". While the TIP framework can be used to understand causes of UACs, it does not provide solutions to overcoming UACs. The more recent knowledge-in-Practice (KIP) framework on the other hand, helps to understand how Social Knowledge Networking (SKN) systems could be used alongside existing health IT systems (e.g., EHRs) to create new social network structures, increase engagement \& learning, and transform TIP. ${ }^{[22-25]}$ Therefore, integrating the TIP and KIP literatures may help to both understand and overcome UACs. For example, the TIP/KIP framework would suggest that a "limited-use-EHR-in-practice" could be transformed into a "collective-problem-solving-EHR-in practice" by using SKN to create new social network structures, and enable engagement, learning, and practice change. ${ }^{[26]}$

The above gleanings suggest that a narrative review of the technology use literature has potential to provide insight into how "technologies-in-practice" may be transformed from a "limited use" to "meaningful use" at the individual user 
level (to address the first problem of interest). However, since technology implementation commonly takes place at an organizational level, it would be important for managers to understand how changes in technology use at the individual user level, could be successfully implemented and sustained in the long run, at the organizational level (to address the second problem of interest). In other words, since the meaningful use of technology needs to go hand-in-hand with successful implementation of technology it would be essential to supplement a narrative review of the technology use literature with a narrative review of the change implementation literature. Lessons learned from both reviews in turn, could be applied to address the two key problems of interest. In summary, the objectives of this paper are to:

- Conduct a narrative review of the literature on technology use to understand how technologies-in-practice may be transformed from "limited use" to "meaningful use".

- Conduct a narrative review of the literature on organizational change implementation to understand how changes in technology use could be successfully implemented and sustained in the longer term.

- Apply lessons learned from the narrative literature reviews to identify strategies for the meaningful use and successful implementation of EHR medication reconciliation technology.

\subsection{Literature on technology use}

The longstanding TIP literature stresses the role of human action in enacting structures of technology use or "technologiesin-practice." According to this view, individuals enact technology use structures through ongoing interactions with the given technology, and since interactions with technology occur within the context of a larger social system, these interactions also serve to enact other social structures, along with the technology use structure. This may include a bureaucratic authority structure or a cooperative structure within a collaborative community. In summary, the TIP framework helps to understand the types of technologies-in-practice that are likely to be enacted under specific institutional conditions (social structures). ${ }^{[16,17]}$

Correspondingly, the TIP framework has been used to understand causes of UACSs of technology (e.g., EHR) implementation e.g., more/new work for clinicians; conflicts between electronic and paper-based systems; and unexpected changes in the power structure. In the past, the TIP lens has been used to trace back UACs of technology implementation to "limited-use-TIP" and "hierarchical network structures"; and likewise UFCs to "collective-problemsolving-TIP" and "collaborative network structures". The
TIP literature also discusses other types of TIP, including "individual-productivity-TIP", process-improvement-TIP" and "improvisation-TIP".

Importantly however, while the TIP framework helps to examine causes of UACs, it does not provide solutions for overcoming UACs. The more recent KIP literature on the other hand, has examined how changes made to social (communication) structures could impact the exchange of knowledge and the creation of new knowledge, to in turn enable collective learning and practice change. Recently, the KIP literature has examined the types of knowledge activated by various types of information and communication technologies. ${ }^{[23-25,27,28]}$ According to this literature, explicit knowledge (i.e., formal systematic knowledge that is easy to communicate) may be best activated through intranets and which create open shared spaces; whereas, tacit knowledge (i.e., knowledge embedded in practices, and critical for innovation), may be best activated through $\mathrm{SKN}$ systems, which have the potential to enable reciprocal communication and collaboration.

For example, SKN systems would allow discussion forums to be organized around specific EHR implementation issues which in turn could be leveraged to activate tacit knowledge for problem solving. Forum topics may include "evidencebased practices", "patient care workflows" and "IT issues". The forum on "evidence-based practices" could be used by hospital administrators to communicate tacit knowledge regarding: (1) the growing importance of completing medication reconciliation on the EHR system during patient care transitions; and (2) the high number of adverse drug events that were encountered in erstwhile medication ordering systems. Knowledge exchange of this type has potential to create shared meaning among hospital administrators and clinical providers in regard to the value of EHR medication reconciliation for patient safety. The forum on "patient care workflows" in turn could be used to encourage physicians, nurses, and pharmacists to establish consensus regarding medication ordering practices. Similarly, the "IT issues" forum could be leveraged to promote reciprocal communication across the administration, medical, and IT departments to enable collective problem solving. In summary, using SKN alongside the existing EHR system has potential to transform an existing "hierarchical" structure into a "cooperative" one, to activate tacit knowledge for collective problem solving. Therefore, introducing an SKN alongside EHR could serve to transform EHR -in-practice from "limited use" to "meaningful use".

It would be relevant to note that embedded in the integrated TIP/KIP framework (see Figure 1) is the important concept 
of "double-loop learning," which has been widely used to support inter-professional learning and teamwork. ${ }^{[29,30]}$ In essence, there are two ways individuals can learn from their experiences: (1) single-loop learning and (2) double-loop learning. Single-loop learning involves connecting a strategy for action with a result. If an action taken yields results that are different to what is expected, single-loop learning, will allow results to be observed and a different approach to be tested. The recurring process of applying a new strategy to achieve an expected outcome may occur several times without success. Running out of strategies may prompt a re-evaluation of the deeper variables governing actions and behaviors. This is called double-loop learning, which views consequences from a wider perspective. Individual values and beliefs are deeply rooted to a professional background, as are the assumptions individuals make about what strategies will be effective in a given situation, or what outcomes will result from any given action. When confronted with an inter-professional misunderstanding, individuals may need to modify the governing variables, i.e., goals and deeper beliefs regarding actions and consequences, to create an attitude that is open to many cultural values and application methods.

In the integrated TIP/KIP framework (see Figure 1), the transformation of technologies-in-practice enabled by SKN technology may be viewed as a manifestation of double-loop learning at the individual user level. Likewise, double-loop learning may also be viewed as key deliverable of SKN technology. In the short run, the SKN may help increase user-engagement in the IT issue of interest (e.g., EHR medication reconciliation), by enabling tacit knowledge exchange (i.e., knowledge linking practice with outcomes), which in turn can promote single-loop learning and practice change (e.g., problem solving through EHRs). The ongoing exchange of tacit knowledge on the SKN in the long run however, has potential to create a system for double-loop learning, which can alter the deeper variables (goals, values, and beliefs) governing practice, thereby producing a fundamental change in the way individual practitioners use the technology, engendering a new "TIP".

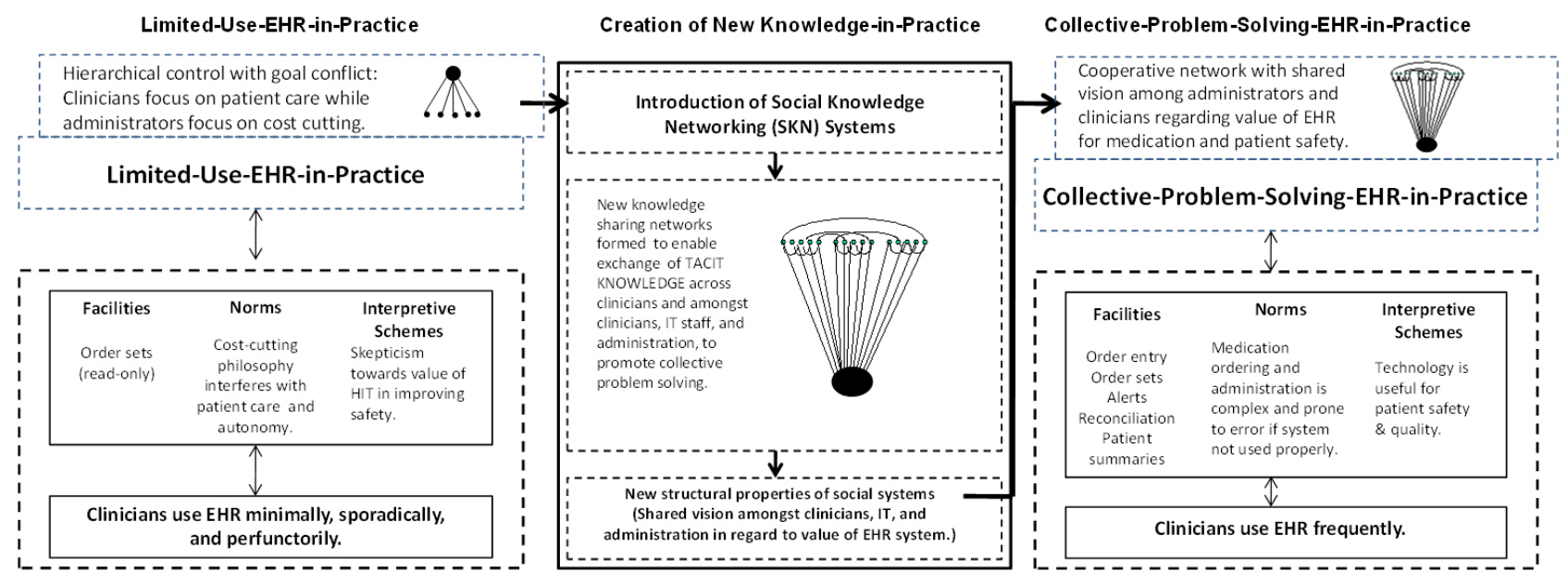

Figure 1. Transforming limited-use-EHR-in-practice to collective-problem-solving-EHR-in-practice through implementation of SKN system

\subsection{Literature on change implementation}

Research on implementing \& sustaining organizational change, emanates from the literature on "Professional Complex Systems", which provides a broader framework for addressing the problem of interest. ${ }^{[31-38]}$ Complex systems theory has repeatedly emphasized that collective learning is an essential pre-requisite to organizational change; and the collective learning in turn, requires the creation of collective tacit knowledge, ${ }^{[35,36]}$ or knowledge embedded in practice (and not easily communicable). Tacit knowledge is often distinguished from explicit knowledge, i.e., formal systematic knowledge (that is easily communicable). According to the complex systems literature, collective tacit knowledge may be the most strategically important kind of organizational knowledge, and mechanisms to create this type of knowledge may be the most crucial task of managers. ${ }^{[35,36,38]}$

To this effect, the complex systems literature has sought to identify the communication structures that may be most conducive for tacit knowledge exchange, collective learning, and change. While earlier research has suggested that peer-to-peer dense communication networks may be most effective for tacit knowledge exchange, ${ }^{[39,40]}$ this literature was restricted to business corporations. Applying the framework to the healthcare organizational context has suggested 
that proactive and periodic top-down communications may be effective for tacit knowledge exchange, collective learning, and change. ${ }^{[31-33]}$ The reasoning is that professional organizations contain multiple professional subgroups that differ in shared expertise and value systems. Since each subgroup performs specific actions to achieve organizational goals, these actions or "subgoals" are reinforced through ongoing in-group communication. ${ }^{[41,42]}$ The end-result is an absence of cognitive linkages across subgoals, as well as between subgoals and organizational goals. In summary, under conditions of change in "Professional Complex Systems", senior administrators must undertake proactive, periodic efforts to create cognitive linkages between subgoals and organizational goals, promote tacit knowledge exchanges across professional subgroups, and enable collective learning and practice change. ${ }^{[32,33,39-44]}$

The Professional Complex Systems framework was recently tested by the authors in a study related to catheter-related bloodstream infection (CRBSI) prevention. ${ }^{[45-47]}$ A prospective study was conducted in two intensive care units at an academic medical center. Both units had low baseline adherence to the Central Line Bundle (CLB), a set of five evidence-based practices for preventing CRBSIs, and higherthan-expected CRBSIs. Periodic top-down communications were conducted over a 52-week period to promote CLB adherence in both units. The study examined: (1) the content $\&$ frequency of communication on CLB at the unit level, through weekly "communication logs" completed by physicians, nurses, and managers; and (2) unit outcomes, i.e., CLB adherence rates through weekly chart reviews. Both units experienced improved outcomes, including increased CLB adherence (particularly, adherence to the fifth CLB component "daily review of line necessity"), and statistically significant (sustained) declines in both CRBSIs and catheter days. Concurrently, both units demonstrated a significant decline in reactive protocol-based communications (e.g., "wear mask before entering patient room") amongst nurses, coupled with a significant increase in proactive risk-reducing communications (e.g., "remove central line" or "switch to peripheral IVs") - between physicians and nurses, over time. Therefore, the tacit knowledge exchange, engagement, and learning across professional subgroups, was associated with a sustained practice change (i.e., daily review of line necessity), which in turn translated to sustained outcomes improvement - significantly reduced central line catheter days and CRBSI rates in both units for over two years following the intervention period.

From the perspective of this paper, it would be relevant to note that similar to the concept of "double-loop learning", the Professional Complex Systems framework is also embed- ded within the Integrated TIP/KIP framework. For example, the change in social network structure from a hierarchical network structure to a coordinated, cooperative structure, following implementation of the SKN system (see Figure 1) serves to operationalize the Professional Complex Systems Framework

\subsection{Lessons learned for EHR medication reconciliation}

The narrative literature reviews in this paper provide substantial insights for addressing the challenge of EHR medication reconciliation. Applying the TIP framework to a healthcare organizational context in which physicians are resistant to completing EHR medication reconciliation, would suggest low physician engagement in managing the patient's medication list, reflecting skepticism regarding the importance of the tool patient safety, translating to limited-use-EHR-inpractice. Concurrently, this problem suggests a hierarchical network structure, reflecting limited communication among hospital administrators and clinicians regarding the importance of adhering to evidence-based medication reconciliation practices during transitions of care.

Essentially, the literature on technology use suggests that implementing a SKN system alongside an existing EHR system might enable a healthcare organization to progress from "limited use" of EHR medication reconciliation technology, to "meaningful use". The rationale is that the SKN would bring together a diverse group of practitioners (physicians, nurses, pharmacists, IT staff, and administrators), to facilitate the exchange of tacit knowledge (practice-based knowledge) on the problem of interest. An example of tacit knowledge in the context of EHR medication reconciliation would be a detailed explication of "how failure to obtain complete medication lists from a transferring institution resulted in a prescription error, causing a significant adverse drug interaction".

Importantly, the embedded concept of "double-loop learning" in the TIP/KIP framework, suggests that in the short run, tacit knowledge exchange (enabled by SKN), would serve to highlight adverse consequences of gaps in practice for patient outcomes; and emphasize the value of adhering to best practices in EHR medication reconciliation, which in turn is expected to increase physician engagement in the patient in the EHR reconciliation process, promote single-loop learning, and enable problem solving through the EHR. From a provider's perspective therefore, the SKN would bring to light systemic issues and their implications, which s/he may not otherwise be aware of, including an explication of the consequences of not adhering to evidence-based practices, for the organization and the individual provider. As such, in the long run, the SKN has potential to create a system 
for double-loop learning, which could fundamentally alter the deeper variables (goals and beliefs) governing the way providers use the EHR system.

Therefore, the technology use literature, including the TIP/KIP framework provides the rationale for using SKN systems to transform EHR medication reconciliation-in-practice from "limited use" to "meaningful use". However, since technology implementation commonly takes place at an organizational level, a key concern would be to ensure successful and sustained implementation of the changes in technology use. According to the literature on organizational change implementation, and particularly, the Professional Complex Systems framework, proactive and periodic top-down communications from senior administrators may be most effective for enabling tacit knowledge exchange, learning, and practice change across professional subgroups in healthcare organizations.

As such, an SKN intervention seeking to enable a health system to transition from "limited use" to "meaningful use" of EHR must have both "top-down" and "bottom-up" elements. In other words, the intervention must be designed such that proactive periodic "top-down" efforts of senior administrators (e.g., SKN Moderators) to promote EHR medication reconciliation, can synergize with "bottom-up" exchange of tacit knowledge by practitioners (e.g., SKN Users), to enable engagement, learning, and practice change (EHR meaningful use). Therefore, an effective SKN intervention design would clearly distinguish the roles \& responsibilities of a small group of SKN Moderators (senior administrators) from a larger group of SKN Users (practitioners) within the healthcare organization.

In addition, it may be helpful for hospitals and health systems to begin with a pilot test of the SKN intervention in a small segment of the organization that is exposed to considerable patient care transitions, e.g., the outpatient, emergency room, and inpatient general medicine service (including the hospitalist service). Additionally, to ensure workflow integration and cost-effective implementation, it would be essential for the SKN system to be integrated into the EHR workflow, primarily from an IT perspective, so that busy clinicians do not have to access multiple disconnected systems for the SKN and EHR. It may also be beneficial for the SKN intervention to focus on select high-risk drugs, e.g., Insulin and Warfarin therapies, to enable the organization to effectively measure the impact of the SKN intervention on outcomes of meaningful use (e.g., EHR medication reconciliation process measures, medication errors, and patient-centered outcome measures, by physician SKN user).

The SKN system in turn, could be designed to have a "bottom-up" issue reporting component (reporting tool) and a "top-down" discussion and knowledge exchange coordination component (SKN tool). The reporting tool could be used to encourage $S K N$ users to report issues or problems of interest related to EHR reconciliation on an ongoing basis, from the frontlines of healthcare delivery. The reporting tool could be designed to comprise of a set of issue categories (or reporting menu) related to EHR medication reconciliation, for SKN users to select from. For example, a relevant challenge faced at the frontlines may be "lack of processes for obtaining patient medication lists from transferring institutions", which in turn may be broadly characterized as an "admission process issue". An example set of "issue categories" related to EHR medication reconciliation therefore, would be: "admission process issue", "discharge process issue", "IT issue", "patient issue", "role-conflict issue", "workflow issue", "resource issue", "near misses", "adverse events", "other issue", etc. This Reporting Menu (which may vary by medication category), may be made available for $S K N$ users under three medication categories: (1) Insulin; (2) Warfarin; and (3) Other Medication. In summary, following from the technology use literature, ongoing use of the reporting tool by $S K N$ users has potential to enable "bottom-up" exchange of tacit knowledge related to EHR medication reconciliation.

The SKN Moderators in turn, would play a key role in facilitating tacit knowledge exchanges related to EHR Medication Reconciliation issues through the SKN tool. Their responsibilities would include: (1) Reviewing submissions on the reporting tool on a regular basis to identify pressing issues related to EHR medication reconciliation for bringing to discussion on the SKN tool; (2) Facilitating discussions on selected issues of interest, which may entail inviting SKN users and other guest experts (as applicable) to participate in moderated discussion forums on the SKN tool; (3) Proactively and periodically, initiating interventions on the SKN tool on a regular basis to promote EHR medication reconciliation, with an emphasis on the priority high-risk drugs, e.g., Insulin and Warfarin therapies; and (4) Identifying key aspects of SKN discussions (e.g., safety issues and improvement opportunities) for bringing to organizational performance improvement meetings for further discussion and action.

An example of a discussion topic on the SKN tool may be "Using a regional Health Information Exchange (HIE) to obtain medication lists for patients who are not registered on SureScripts ${ }^{T M}$ (a nation-wide Pharmacy registry)" This topic may have been prompted by a user report of an "IT Issue" under Insulin. The issue may have been that providers often have difficulty obtaining up-to-date medication lists from patients whose pharmacies are not registered on SureScriptsTM. An idea for resolving this issue may be to use 
the regional HIE for this purpose. This forum in turn, may involve a resident, an IT specialist, pharmacy technicians, nurses, and ER physicians. The discussion group in turn, may be moderated by the Chief Medical Information Officer at the institution.

Broadly speaking, SKN Moderators would leverage various features of the SKN tool to: (1) facilitate tacit knowledge exchange on prominent issues related to EHR medication reconciliation, (e.g., failure to reconcile Warfarin dosage changes in the ER; or distinguishing different types of Insulin; or a discussion of a near-miss or adverse event); (2) educate providers on the value of medication reconciliation in reducing medication errors, with the support of in-house experts; (3) engage clinicians in discussions related to meaningful use of EHR medication reconciliation; (4) enable IT unit specialists to explain the rationale behind features of the EHR medication reconciliation system to clinicians; (5) enable the patient-and-family-centered care unit to share the patient perspective on medication reconciliation; and (6) provide performance reports related to medication reconciliation to highlight opportunities for improvement. On the other hand, the main responsibility of SKN Users would be to report issues encountered with EHR Reconciliation on an ongoing basis, through the reporting tool.

While the proactive and periodic interventions by SKN Moderators on the SKN tool would enable "top-down" communication of organizational issues related to medication reconciliation, the ongoing "issue reports" submitted by $S K N$ Users on the reporting tool, would enable "bottom-up" identification of frontline issues related to EHR medication reconciliation. In summary, an SKN system that is integrated into the EHR workflow has potential to provide a platform for tacit knowledge exchange, engagement, learning and practice change (EHR meaningful use), at the frontlines of care delivery.

\section{Conclusions}

The problem of interest in this paper is low physician engage ment in performing EHR medication reconciliation, translating to limited use of EHR medication reconciliation technology. While the technology use literature provides a rationale for using SKN technology to facilitate meaningful use of EHR medication reconciliation technology; the organizational change implementation literature provides insights for the effective design and implementation of an SKN system. This literature suggests that an SKN system must enable proactive periodic "top-down" efforts of senior administrators (e.g., SKN Moderators) to promote EHR medication reconciliation, to synergize with "bottom-up" exchange of tacit knowledge by practitioners (e.g., SKN Users), to enable engagement, learning, and practice change (EHR meaningful use). It may be beneficial to incorporate a bottom-up "issue reporting" component (reporting tool) and a top-down knowledge exchange coordination component (SKN tool) into the SKN system and integrate the SKN system into the EHR workflow. While SKN users (practitioners) would use the reporting tool to report issues or problems of interest related to EHR reconciliation on an ongoing basis, SKN Moderators (senior administrators) would play a key role in coordinating tacit knowledge exchange by bringing select issues of interest to SKN discussion forums, to enable engagement, problem solving, learning, and practice change (i.e., EHR meaningful use).

In summary, the literature reviews in this paper serve the dual purpose of: (1) providing insights into strategies for meaningful use and successful implementation of EHR medication reconciliation technology; and (2) providing insights for future research in this area. A logical next step would be to conduct a case study or a pilot study incorporating the lessons learned from this review for facilitating the meaningful use \& successful implementation of EHR technology, through the use of SKN technology. Such studies would have the potential to generate evidence-based management strategies for enabling provider engagement, learning, EHR meaningful use and successful implementation, for dissemination to healthcare organizations. Moreover, preliminary studies of this nature could also set the stage for future large-scale experiments on the impact of SKN systems on the meaningful use of EHR technology. Future studies of this nature could carry important policy implications, because if the hypothesis holds, federal EHR vendors could be encouraged and incentivized to incorporate SKN features into EHR systems.

\section{REFERENCES}

[1] Bates DW, Boyle DL, Vliet MBV, et al. Relationship between medication errors and adverse drug events. Journal of General Internal Medicine. 1995; 10(4): 199-205. PMid: 7790981. http: //dx.doi.org/10.1007/BF02600255

[2] Bates DW, Cullen DJ, Laird N. Incidence of adverse drug events and potential adverse drug events. JAMA the Journal of the American Medical Association. 1995; 1(1): 117. http://dx.doi.org/10. 1016/s1075-4210(05)80011-2

[3] Brennan TA, Leape LL, Laird NM, et al. Incidence of adverse events and negligence in hospitalized patients. Results of the Harvard Medical Practice Study I. New England Journal of Medicine. 1991; 
324(6): 377-384. http://dx.doi.org/10.1056/NEJM1991020 73240604

[4] Institute of Medicine Committee on Identifying and Preventing Medication Errors. Aspden P, Wolcott J, Bootman JL, Cronenwett LR, eds. Preventing Medication Errors: Quality Chasm Series. Washington, DC: The National Academies Press; 2007.

[5] Leape LL, Brennan TA, Laird N, et al. The nature of adverse events in hospitalized patients. Results of the Harvard medical practice study II. New England Journal of Medicine. 1991; 324: 377-384. PMid: 1824793. http://dx.doi.org/10.1056/NEJM1991020 73240605

[6] Institute of Medicine To Err is Human: Building a Safer Health System. Washington: DC National Academy Press; 1999.

[7] Barnsteiner JH. Medication Reconciliation. In: Hughes RG, editor. Patient Safety and Quality: An Evidence-Based Handbook for Nurses. Rockville (MD): Agency for Healthcare Research and Quality (US); Chapter 38. 2008. Available from: http://www.ncbi.nlm.nih.g ov/books/NBK2648/

[8] World Bank. World Development Report 2000/2001: Attacking poverty. Washington, DC: World Bank. 2000. http://www.ihi.org/topics/adesmedicationreconci liation/Pages/default.aspx

[9] Mueller SK, Kelly Cunningham S, Sunil K, et al. Hospital-based medication reconciliation practices: a systematic review. Journal of the Electrochemical Society. 1985; 132(10): 1057-69.

[10] Pronovost PB, Schwarz M, Wyskiel RM, et al. Medication reconciliation: A practical tool to reduce the risk of medication errors. Journal of Critical Care. 2003; 18(4): 201-205. PMid: 14691892. http://dx.doi.org/10.1016/j.jcrc.2003.10.001

[11] American Hospital Association. HIT Incentive Payment Program: Definition of 'Meaningful Use. 2010. Available from: http://www . aha.org/content/00-10/10-ib-def-meaning-use.pdf

[12] Boockvar KS, Santos SL, Kushniruk A, et al. Medication reconciliation: barriers and facilitators from the perspectives of resident physicians and pharmacists. Journal of Hospital Medicine. 2011; 6(6): 329337. PMid: 21834114. http://dx.doi.org/10.1002/jhm. 891

[13] Grossman JM, Gourevitch R, Cross ADA. Hospital Experiences Using Electronic Health Records to Support Medication Reconciliation. Mathematica Policy Research Reports. 2014.

[14] Sanchez HS, Sadie SS, Santos SL, et al. Implementing medication reconciliation from the planner's perspective: a qualitative study. BMC Health Services Research. 2014; 14: 290. PMid: 24996538. http://dx.doi.org/10.1186/1472-6963-14-290

[15] Sluisveld NV, Zegers M, Natsch S, et al. Medication reconciliation at hospital admission and discharge: insufficient knowledge, unclear task reallocation and lack of collaboration as major barriers to medication safety. BMC Health Services Research. 2012; 12(3): 1-12. http://dx.doi.org/10.1186/1472-6963-12-170

[16] Orlikowski W. Using technology and constituting structures: a practice lens for studying technology in organizations. Organization Science. 2000; 11(4): 404-428. http://dx.doi.org/10.1287/ors c. 11.4 .404 .14600

[17] Orlikowski W, Barley S. Technology and institutions: what can research on information technology and research on organizations learn from each other? Management Information Systems Quarterly. 2001; 25: 145-165. http://dx.doi.org/10.2307/3250927

[18] Campbell E, Sittig D, Ash J, et al. Types of unintended consequences related to computerized provider order entry. Journal of the American Medical Informatics Association. 2016; 13(5): 547-556. PMid: 16799128. http://dx.doi.org/10.1197/jamia.M2042

[19] Harrison M, Koppel R, Bar-Lev S. Unintended consequences of information technologies in health care-an interactive sociotechnical analysis. Journal of the American Medical Informatics Association 2007; 14(5): 542-549. PMid: 17600093. http://dx.doi.org/10. 1197/jamia.M2384

[20] Jones SS, Koppel R, Ridgely MS, et al. Guide to Reducing Unintended Consequences of Electronic Health Records. Prepared by RAND Corporation under Contract No. HHSA290200600017I, Task Order \#5. Agency for Healthcare Research and Quality (AHRQ). Rockville, MD. 2011.

[21] Rollins G. Unintended consequences: identifying and mitigating unanticipated issues in EHR use. Journal of AHIMA. 2012; 83(1): 28-32. PMid: 22375477.

[22] Rangachari P. Overcoming the Unintended Adverse Consequences of Implementing Health IT through Human Resource and Knowledge Management. In Blair JD, Fottler MD, Savage GT (Eds.). Strategic Human Resource Management in Health Care. Advances in Health Care Management. 2010; 9: 163-194. http://dx.doi .org/10.11 08/s1474-8231(2010)0000009011

[23] Barrett M. Information Technology, Organizational Change, and New Modes of Organizing. In A. Salazar; Sawyer, S (Ed.). Handbook of Information Technology in Organizations and Electronic Markets. Singapore: World Scientific Publishing; 2007. http: //dx.doi.org/10.1142/9789812707628_0003

[24] Burgnoon J, Bonito J, Bengtson B, et al. Testing the Interactivity Model: Communication Processes, Partner Assessments and the Quality of Collaborative Work. Journal of Management Information Systems. 2000; 16(3): 33-56. http://dx.doi .org/10.1080/074 21222.1999.11518255

[25] Qureshi S, Keen P. Organizational Transformation by Activating Knowledge: The Medicating Role of Collaborative Technologies. In A. Salazar; Sawyer, S (Ed.). Handbook of Information Technology in Organizations and Electronic Markets. Singapore: World Scientific Publishing; 2007. http://dx.doi .org/10.1142/97898127076 28_0010

[26] Rangachari P. Using social knowledge networking technology to enable meaningful use of electronic health record technology in hospitals \& health systems: A review article. Journal of Hospital Administration. 2014; 3(6): 66-78. http://dx.doi.org/10.5430 /jha.v3n6p66

[27] Lobach D, Sanders GD, Bright TJ, et al. Enabling Health Care Decision-making through Clinical Decision Support and Knowledge Management. Evidence Report No. 203. AHRQ Publication No. 12-E001-EF. Rockville (MD): Agency for Healthcare Research and Quality; 2012.

[28] Robey D, Khoo H, Powers C. Situated Learning in Cross-Functional Virtual Teams. IEEE Transactions on Professional Communications. 2000; 42(1): 51-66. http://dx.doi .org/10.1109/47.826416

[29] Argyris C, Schon D. Organizational Learning: A Theory of Action Perspective. Reading, MA: Addison-Wessley; 1978.

[30] Argyris C. Overcoming Organizational Defenses: Facilitating Organizational Learning. Boston: Allyn \& Bacon, Prentice-Hall; 1990

[31] Anderson A, McDaniel R. Managing health care organizations: where professionalism meets complexity science. Health Care Management Review. 2000; 25(1): 83-92. PMid: 10710732. http: //dx.doi.org/10.1097/00004010-200001000-00010

[32] Rangachari P. Knowledge sharing networks related to hospital quality measurement and reporting. Health Care Management Review. 2008; 33(3): 253-263. PMid: 18580305. http://dx.doi.org/10.1097 /01. HMR.0000324910.26896.91

[33] Rangachari P. Knowledge sharing and organizational learning in the context of hospital infection prevention. Quality Management in Health Care. 2010; 19(1): 34-45. PMid: 20042932. http: //dx.doi.org/10.1097/QMH.0b013e3181ccbd1d 
[34] Damschroder LJ, Aron DC, Keith RE, et al. Fostering implementation of health services research findings into practice: a consolidated framework for advancing implementation science. Implementation Science. 2009; 4: 50. PMid: 19664226. http://dx.doi.org/10. 1057/gpp. 2008.6

[35] Plsek P. Redesigning Health Care with Insights from the Science of Complex Adaptive Systems. In IOM, Crossing the Quality Chasm. 2001; 309-322, Appendix B.

[36] Plsek P. Complexity, Leadership, and, Management in Healthcare Organizations. British Medical Journal. 2001; 323(7315): 746-9. PMid: 11576986. http://dx.doi.org/10.1136/bmj .323.7315.746

[37] Ramanujam R, Rousseau D. The challenges are organizational not just clinical. Journal of Organizational Behavior. 2006; 27(7): 811827. http://dx.doi.org/10.1002/job. 411

[38] Spender J. Making knowledge the basis of a dynamic theory of the firm. Strategic Management Journal. 1996; 17: 45-62. http: //dx.doi.org/10.1002/smj.4250171106

[39] Burt R. Network Structure of Social Capital. In R. I. Sutton, Staw, B.M (Eds.), Research in Organizational Behavior, Vol. 22. Greenwich, CT: JAI Press; 2000. http://dx .doi .org/10.1016/s0191 -3085 (00) 22009-1

[40] Hansen MT. The search-transfer problem: Role of weak ties in sharing knowledge across organizational units. Administrative Science Quarterly. 1999; 44(1): 82-111. http://dx.doi.org/10.2307/2 667032
[41] Benveniste G. Professionalizing the Organization. San Francisco, CA: Jossey Bass; 1987.

[42] March J, Simon H. Organizations: John Wiley \& Sons Inc; 1958.

[43] Kogut B. The Network as knowledge: generative rules and the emergence of structure. Strategic Management Journal. 2000; 21(Special Issue): 405-425. http://dx . doi .org/10.1002/(SICI) 1097-0 266(200003) $21: 3<405:$ : AID-SMJ103>3 . 0.CO; 2-5

[44] Krackhardt D. The Strength of Strong Ties. In Nohria N, Eccles RG (Ed.), Networks and Organizations: Structure, Form, and Action. Boston: Harvard Business School Press; 1992.

[45] Rangachari P, Rissing P, Rethemeyer RK. Awareness of evidencebased practices alone does not translate to implementation: Insights from implementation research. Quality Management in Health Care. 2013; 22(2): 117-125. PMid: 23542366. http://dx.doi.org/10. 1097/QMH . 0b013e31828bc21d

[46] Rangachari P, Madaio M, Rethemeyer RK, et al. The evolution of knowledge exchanges enabling successful practice change in two intensive care units. Health Care Management Review. 2015; 40(1): 65-78. PMid: 24153028. http://dx.doi.org/10.1097/HMR.0 000000000000001

[47] Rangachari P, Madaio M, Rethemeyer RK, et al. Cumulative impact of periodic top-down quality improvement communications on infection prevention practices \& outcomes in two units. Health Care Management Review. 2015; 40(4): 324-36. PMid: 25120195. http://dx.doi.org/10.1097/HMR.0000000000000038 